\title{
Differences in patient-reported experiences of care by race and acculturation status
}

Memoona Hasnain, ${ }^{1,2}$ Alan Schwartz, ${ }^{2}$ Jorge Girotti, ${ }^{2}$ Angela Bixby,${ }^{3}$ Luis Rivera, ${ }^{3}$

and the UIC Experiences of Care Project Group*

${ }^{1}$ Department of Family Medicine

${ }^{2}$ Department of Medical Education

${ }^{3}$ College of Medicine

University of Illinois at Chicago, Chicago, Illinois

\section{Corresponding author:}

Memoona Hasnain, MD, MHPE, PhD

Associate Professor \& Director of Research

Director, Patient-centered Medicine Scholars Program

Department of Family Medicine (MC 663)

College of Medicine, University of Illinois at Chicago

1919 W. Taylor Street, Chicago, IL 60612-7309

Phone: 1-312-996-8214

FAX: $1-312-996-2579$

Email: memoona@uic.edu

Key Words: Patient-centered care, acculturation, cultural competence, quality care

Running Head: Race \& Acculturation

Submission date: April 12, 2012; 1st Revision submitted: August 15, 2012, $2^{\text {nd }}$ Revision submitted September 6, 2012

Funding Source: Grant number 63821 from the Robert Wood Johnson Foundation

Word count: Abstract (152), Article (2930)

Number of tables: 4

Disclosure of conflict of interest: None of the authors have any conflict of interest to disclose.

Acknowledgement: This research was funded [in part] by grant number 63821 from the Robert Wood Johnson Foundation.

*The UIC Experiences of Care Project Group consists of Alan Schwartz, Memoona Hasnain, Jorge Girotti, Angela Bixby, Bianca Castellano, Michelle M. Garrido, Marjorie A. Girotti, Joe Gomez, Ariel Leifer, Luis Rivera, Vamsi Vasireddy. 


\section{INTRODUCTION}

Asking patients to rate the quality of their health care experiences is increasingly gaining emphasis in the ongoing evaluation of the provision of health care. Given persistent racial/ethnic disparities in health status in the United States, access to and utilization of health care, as well as the quality of care [1], it is crucial to explore differences in patients' perception of the quality of care across ethnically diverse populations. These questions are particularly important when studies indicate that some non-white patients report better care experiences in situations where they are known to receive lower-quality care, while others do not [2-5]. One recent study [6] suggests both an important role for differential item use by respondents of different ethnicities and approaches to survey validation to measure and control for differential use, including varying response scales, measuring of patient expectations, and controlling for interrelated factors, such as education level.

Acculturation, a process whereby the attitudes and/or behaviors of people from one culture are modified as a result of contact with a different culture, is an important variable for consideration in the quality of health care delivery for immigrant patients. Acculturation has been shown to be a correlate of access to care, use of health care services, perceptions, health behaviors and outcomes [7-13]. The association of acculturation with various aspects of health care access, utilization and outcomes reiterates the need for not only better tailoring the provision of health care to meet the needs of the different patient groups but also to designing more rigorous evaluation tools to accurately capture patient's perceptions and reduce bias due to instrument construction or delivery as well as responder characteristics. A recent systematic review of the literature strongly recommends additional research to better understand the influence of acculturation on immigrant health [14]. Specifically for Hispanic patients, a rapidly 
increasing minority group in the United States, impact of acculturation on health is complex and poorly understood. Emerging research in measuring acculturation also recognizes the multidimensionality of the acculturation process and takes into account the issue of bicultural development. There is a paucity of literature utilizing studies with methodological rigor exploring associations between acculturation and patient-reported experiences of care.

\section{Theoretical/conceptual framework}

Although acculturation-related differences in health care utilization and perceptions have been described, acculturation research has not yet produced a clearly defined conceptual model explaining the role of acculturation on patient perceptions of quality of care [15-16]. Some generalizations seem logical and intuitive, such as the idea that immigrants who have not been extensively acculturated in the U.S. health care system with its emphasis on patient autonomy are likely to regard physicians with greater deference than those who have. The contextual specificity of acculturative processes, however, leads us to be cautious about adopting such generalizations a priori. Accordingly, the framework for this study was primarily exploratory. We assume that the impact of race and acculturation may be not only on access (which providers are accessible by which patients) and provider behavior (how providers care for specific patients), but also on perceptions of care (how care is perceived by different patient groups). To better focus on care perceptions, we studied a large sample of patients varying in race (African-American, Hispanic, or Caucasian) and, within Hispanic patients, acculturation status, but all of whom were provided care by a common set of providers, thus controlling for access and provider practice. Hence, this study represents a unique contribution to extant literature. 


\section{METHODS}

\section{Setting and Participants}

The study included adult patients seen in four outpatient Family Medicine clinics at an urban academic institution in Midwest, USA. The clinics have over 6,000 combined patient visits each month. Overall, approximately $48 \%$ of patients served by the study clinics are AfricanAmerican, 25\% are Hispanic, 20\% are Caucasian, and 7\% are of other or mixed ethnicities.

\section{Study Design}

A cross-sectional in-person survey design was used to administer a face-to-face survey to study participants. The University of Illinois at Chicago Institutional Review Board reviewed and approved this research.

\section{Measures}

Three instruments were used to collect information on three core measures: 1) patient experiences of care; 2) self-reported health status; and 3) degree of acculturation (for Hispanic patients).

Patient experiences of care were measured with the Consumer Assessment of Healthcare Providers and Systems (CAHPS) Clinician \& Group Survey Adult Primary Care instrument (CAG) which is designed to measure experiences with care provided by a clinician and/or medical group [17]. This widely-used instrument assesses a number of dimensions of health care services. To simplify interpretation of the data and assure reliability of results questions that assess a common theme are grouped together as "composites". The core items and selected supplemental items related to "Other doctors and providers at your doctor's office", "Provider communication", "Recommend doctor", and "Shared decision-making" were included in the 
survey. Supplemental items were chosen to facilitate the analysis without excessively

lengthening the instrument.

Self-reported health status was measured with the Medical Outcomes Scale Short Form (SF)-12 instrument [18]. The SF-12v2 scoring algorithm was used for the scale, as recommended by its authors.

Acculturation was measured for Hispanic participants by the 12-item language proficiency subscale of the Bidimensional Acculturation Scale for Hispanics [19]. This scale was chosen for its strong psychometric properties, its correlation with more complete measures of acculturation, its short length, and its ability to provide a more nuanced understanding of acculturation than unidimensional scales.

Detailed information about the three instruments used in this study is available from the source documents [17-19]. Spanish and English versions of all three instruments in the form of a single survey were made available to the participants. Based on authors' prior work, it was estimated that participants would need 30-40 minutes to complete the survey. The surveys were administered by bilingual (English and Spanish) interviewers who were trained as study research assistants.

\section{Data Collection Procedures}

A sample size of 300 patients per ethnic group was planned on the basis of CAHPS recommendations for measurement reliability among sample groups. Thus, the overall target sample size was 900 patients, stratified by ethnic group (300 African American, 300 Hispanic, and 300 Caucasian). 
Adult patients in participating outpatient Family Medicine clinics were invited to participate in the study. After informed consent, patients who agreed to participate in the study were asked to complete the survey instruments in a face-to-face interview with a bilingual researcher at their clinic, before or after an appointment. Each instrument was provided in both Spanish and English; the patients selected the language in which they preferred to complete the survey. Face-to-face interviews, although more time-consuming, were chosen as they are likely to yield a greater response rate and better data quality than mail or telephone-based approaches. Responses from patients surveyed in this project were recorded anonymously, without any identifiers. Data collection took place between May 2008 and February 2010.

\section{Data Analysis}

The final data set included, for each patient, CAHPS Clinician and Global Survey items, SF-12 health status items, and, for Hispanic patients, the Bidimensional Acculturation Scale items. Responses to CAHPS core items were used to compute the CAHPS Global Rating, overall rating for other providers, and CAG composite scores for timely appointments, communication, follow-up, and office staff as per the CAG scoring manual. Responses to CAHPS supplemental items were used to create supplemental composite scales for other providers, provider communication, and shared decision making (see footnotes to Table 3 for the items used to compute each composite score).

Responses to SF-12 items were used to compute the physical component score (PCS) and mental component score (MCS) per the SF-12v2 scoring manual. Responses to the Bidimensional Acculturation Scale items for Hispanic patients were used to classify patients, following the terminology of Marin and Gamba [19] as unacculturated (high score in the Hispanic domain, low score in the non-Hispanic domain), acculturated (low score in the 
Hispanic domain, high score in the non-Hispanic domain), or biculturated (high score in both Hispanic and non-Hispanic domains).

Differences in CAHPS and SF-12 scores were compared among ethnicity/acculturation groups using one-way analysis of variance (ANOVA) with six planned contrasts among pairs of groups. To the degree that CAHPS responses reflect construct-irrelevant ethnic differences in CAHPS survey-taking rather than true differences in experienced health care, we expected that CAHPS scores will be predicted by ethnicity (and/or acculturation, for Hispanic patients) even when controlling for other demographic and health status predictors. These predictions were tested by fitting ordinary least squares linear regression models to CAHPS scores, with demographic variables (ethnic/acculturation group, sex, age, education) entered as dummy-coded predictors, and SF-12 physical and mental component scores entered as continuous predictors.

Caucasian ethnicity, male sex, age 18-24, and education less than a high school diploma were used as the baseline categories for dummy codes. Age categories over 45 were collapsed into a single category. We compared the standardized coefficients for ethnic/acculturation group with other predictors in each model. 


\section{RESULTS}

\section{Participant Characteristics}

Eight hundred and eighty one patients (303 (34\%) African-American, 271 (31\%) Hispanic, 291 (33\%) Caucasian, 16 (2\%) missing race), recruited from the participating study clinics, completed the study questionnaires. Table 1 presents the demographic characteristics of the respondents overall and by ethnicity; Table 2 presents demographic characteristics by clinic site. All Hispanic patients were either unacculturated $(90 / 271-33.21 \%)$ or biculturated $(181 / 271$ - 66.79\%). Caucasian and biculturated Hispanic respondents tended to be younger than AfricanAmerican or unacculturated Hispanic respondents $\left(\chi^{2}(6)=102, p<.001\right)$. Unacculturated Hispanic respondents were much more likely to be female than other respondents $\left(93 \%\right.$ vs. $68 \%, \chi^{2}(1)=25$, $\mathrm{p}<.001)$, and to have lower education levels $\left(\chi^{2}(5)=351, p<.001\right)$.

Table 3 summarizes the SF-12 and CAHPS CAG scores for the sample and for each group. The "other providers" overall rating and the "other providers" composite scale were computed over the 409 patients $(46 \%)$ who reported seeing other providers during their visit. Although one-way ANOVA with planned contrasts found several significant ethnic differences in SF-12 PCS and MCS scores, most of these differences disappeared when regression analyses were performed to control for other demographic predictors, notably age and education. SF-12 PCS scores were significantly lower for African-American (mean 48.9, SD 10.2) and unacculturated Hispanic patients (mean 47.6, SD 8.3) than Caucasian (mean 53.3, SD 7.3) or biculturated Hispanic patients (mean 52.0, SD 6.9), and were also lower for patients 25 years and older (mean 49.4, SD 9.7) than patients 18-24 (mean 53.3, SD 6.0; unequal-variance $\mathrm{t}(866)=7.4$, $\mathrm{p}<.001$ ), and higher for patients with any college education (mean 51.9, SD 8.2) than for patients with no college education (mean 47.9, SD 9.5, unequal-variance $t(327)=5.5, p<.001$ ). SF-12 
MCS scores were higher for African-American (mean 53.2, SD 9.4) and Caucasian (mean 52.6, SD 10.4) patients than Hispanic patients either unacculturated (mean 47.2, SD 11.4) or biculturated (mean 49.3, SD 10.9) and were also lower for patients 25 years and older (mean 50.3, SD 10.8) than patients 18-24 (mean 53.4, SD 9.6, unequal-variance $\mathrm{t}(751)=4.3, \mathrm{p}<.001$ ), and higher for patients with any college education (mean 52.7, SD 9.6) than for patients with no college education (mean 47.8, SD 12.1, unequal-variance $\mathrm{t}(307)=5.5, \mathrm{p}<.001)$.

\section{Predictors of CAHPS Scores}

Table 4 summarizes the regression models. The first two columns, "overall” and "recommend", each reflect the patient's global perception of their physician. The CAG "overall" score was significantly associated with SF-12 MCS (beta=.198, $\mathrm{p}<.001)$ and being in the Hispanic, unacculturated group (beta=.193, $\mathrm{p}=.006$ ). The CAG "recommend" score was also significantly associated with being in the Hispanic, unacculturated group (beta=.139, p=.049).

The "shared decision making", "communication", and "provider communication" scores reflect patient perceptions of physician behaviors in the clinical encounter. The CAG "shared decision making" score was significantly associated with being male (beta=-.137, $\mathrm{p}=.006$ ), being of age 45 or older (beta $=.135, \mathrm{p}=.036$ ), being in the Hispanic, unacculturated group (beta $=.160$, $\mathrm{p}=.015)$ and being in the Hispanic, biculturated group (beta $=.218, \mathrm{p}<.001)$. The CAG “communication" score was significantly associated with SF-12 PCS (beta=.147, p=.020) and SF-12 MCS (beta=.200, $\mathrm{p}<.001$ ). The CAG "provider communication" score was not significantly associated with any predictor.

The remaining CAG scores deal with the patient's experience of other providers they may have seen at the visit, staff, and the ease of obtaining appointments. The CAG "other providers" score was significantly associated with age $45+($ beta= $=155, \mathrm{p}=.023)$ and SF-12 MCS 
(beta $=.208, \mathrm{p}<.001$ ). In particular, there was no relationship with ethnicity/acculturation. The CAG "other providers overall" score was significantly associated with being unacculturated Hispanic (beta $=.136, \mathrm{p}=.044)$, age $45+(\mathrm{beta}=.183, \mathrm{p}=.006)$, having greater than a 4-year college education (beta=-.223, $\mathrm{p}=.015)$, SF-12 PCS (beta $=.149, \mathrm{p}=.015$ ) and SF-12 MCS (beta $=.300$, $\mathrm{p}<.001) .{ }^{1}$ The CAG "helpful staff" score was significantly associated with male gender (beta $=.122, \mathrm{p}=.018$ ), unacculturated Hispanic (beta $=.168, \mathrm{p}=.015$ ), biculturated Hispanic (beta $=.141, \mathrm{p}=.025$ ), and SF-12 MCS (beta=.133, $\mathrm{p}=.011$ ). The CAG "getting appointments" score was significantly associated with male gender (beta $=.128, \mathrm{p}=.011)$ SF-12 PCS (beta $=.180$, $\mathrm{p}=.003$ ), and SF-12 MCS (beta=.266, $\mathrm{p}<.001$ ). In particular, there was no relationship with ethnicity/acculturation.

\footnotetext{
${ }^{1}$ At the suggestion of an anonymous reviewer, we also ran a series of regressions that included interaction terms for gender x ethnic category. For the "other providers overall" outcome only, one of these interaction terms (male $\mathrm{x}$ biculturated Hispanic) was significant (and negative), and the model with the interaction terms also demonstrated significant positive effects of male gender, unacculturated Hispanic, and biculturated Hispanic, along with the same patterns of coefficients for age, education, and SF-12 composites as in the main effects model. The marginal effect of being a biculturated Hispanic male in that model would be lower "other providers overall" ratings relative to other groups.
} 


\section{DISCUSSION}

Measurement of "Quality" of health care is an evolving field that has attracted much attention in recent years. The Institute of Medicine describes "quality care" as "The degree to which health services for individuals and populations increase the likelihood of desired health outcomes and are consistent with current professional knowledge" [20]. The questions grappling health care providers, researchers and policy makers in the related arena of health disparities span a wide range of issues related to tailoring of health care services to better meet the needs of all patients, especially those belonging to minority groups. Accurately capturing patients' viewpoints regarding the quality of care they receive is a critically important element in this regard. Existing research does not provide a clear answer to questions such as, to what degree are different populations having difference experiences, and equally importantly, to what degree are different populations having similar experiences but reporting them differently?

The primary aim of this study was to explore the role of race and acculturation in patients' perceptions of the quality of care that they received in a primary care setting. Patients' self-perceived physical and mental health-status were found to be important predictors of certain experiences of care variables. After controlling for health status and other demographic variables, race and acculturation were significantly associated with several CAG measures: overall provider rating, recommending provider and shared decision making, as well as ratings of other providers overall and helpfulness of staff. Notably, race and acculturation were not associated with ratings of physician communication.

Past research [6] has suggested that ethnic differences in perceptions of care may reflect differences in responding to survey instruments, rather than true differences in care, and may cast doubt on the validity of the instruments. In this study, we attempted to control for provided care 
(through using a common provider pool) and differences in health status (through SF-12 measurement). For several of our experience of care outcomes, we found no effect of race/ethnicity once we controlled for health status (and, in some cases, other demographic factors). Overall ratings of providers were uniformly higher for Hispanic patients (and especially high for unacculturated Hispanic patients), and ratings of shared decision making behaviors by the provider were also higher for Hispanic patients. A recent qualitative study that compared Hispanic and Non-Hispanic Whites seems to have found some results consonant with ours, albeit, without the acculturation nuance [21].

Our findings add new information regarding the role of acculturation in patient-reported experience of care. In our study, Hispanic patients gave significantly higher ratings for the overall global rating for their provider and expressed greater interest in shared decision making than members of other groups. These findings are consistent with our conceptual framework which indicates that immigrants who have not been extensively acculturated in the U.S. health care system with its emphasis on patient autonomy are likely to regard physicians with greater deference than those who have.

Regarding self-perception of health, the unacculturated Hispanic patients in our study gave the lowest ratings for both mental and physical health. This is consistent with past research across different immigrant groups, including Hispanics, which indicates that immigrants with higher acculturation tend to have higher self-reported health [22-25]. In our study, this difference was no longer significant once age and education were controlled.

\section{Study Limitations}

Despite the common provider pool serving our study populations, there may very well be differences in the quality of care provided by specific providers. Moreover, patients may self- 
select to providers with whom they are comfortable (as suggested by high overall ratings of providers across groups), which may create a ceiling effect in our ability to measure differences in perceived quality of care by individual providers. Further studies should examine providerlevel data to adjust for provider variables including demographics, training level, ethnicity and additional features specific to this provider pool, and should consider studying new patients or patients with limited provider choice among whom self-selection biases are less likely. Future research could also stratify patients by their primary conditions and comorbidities, stratify Hispanic subgroups (e.g., Mexicans, Peurto Ricans, Cubans) and include other immigrant groups. An additional area for future research could also explore patient-reported experiences of care in different clinical disciplines. Past research by the first two investigators on patientprovider fit regarding preferences for care indicated differences in preferences between patients in family medicine and internal medicine [26].

\section{Conclusions}

Research on acculturation's impact on Hispanic patients' health care experiences is limited. This study advances answers to some current gaps in research by clarifying the role of acculturation in patients' perceptions of the quality of care they receive. The information gleaned from this study should help health care providers and policy makers in better understanding the role of race and acculturation in the feedback that patients provide. This in turn should contribute to developing best-practices for patient-physician interaction, overall health care delivery and continuous improvements in quality of care. 


\section{References:}

1. Institute of Medicine: Unequal Treatment: Confronting Racial and Ethnic Disparities in Health Care. Washington, DC: National Academy Press; 2002.

2. Lurie N, Zhan C, Sangl J, Bierman AS, Sekscenski ES. Variation in racial and ethnic differences in consumer assessments of health care. Am J Manag Care. 2003 Jul;9(7):502-9.

3. Weech-Maldonado R, Morales LS, Elliott M, Spritzer K, Marshall G, Hays RD. Race/ethnicity, language, and patients' assessments of care in Medicaid managed care. Health Serv Res. 2003 Jun;38(3):789-808.

4. Weech-Maldonado R, Elliott MN, Morales LS, Spritzer K, Marshall GN, Hays RD. Health plan effects on patient assessments of Medicaid managed care among racial/ethnic minorities. J Gen Intern Med. 2004 Feb;19(2):136-45.

5. Dayton E, Zhan C, Sangl J, Darby C, Moy E. Racial and ethnic differences in patient assessments of interactions with providers: disparities or measurement biases? Am J Med Qual. 2006 Mar-Apr;21(2):109-14.

6. Hausmann LR, Kressin NR, Hanusa BH, Ibrahim SA. Perceived racial discrimination in health care and its association with patients' healthcare experiences: does the measure matter? Ethn Dis. 2010 Winter;20(1):40-7.

7. Lara M, Gamboa C, Kahramanian MI, Morales LS, Bautista DE. Acculturation and Latino health in the United States: a review of the literature and its sociopolitical context. Annu Rev Public Health. 2005;26:367-97. 
8. Cheng EM, Chen A, Cunningham W. Primary language and receipt of recommended health care among Hispanics in the United States. J Gen Intern Med. 2007 Nov;22 Suppl 2:283-8.

9. DuBard CA, Gizlice Z. Language spoken and differences in health status, access to care, and receipt of preventive services among US Hispanics. Am J Public Health. 2008 Nov;98(11):2021-8.

10. Ghaddar S, Brown CJ, Pagán JA, Díaz V. Acculturation and healthy lifestyle habits among Hispanics in United States-Mexico border communities. Rev Panam Salud Publica. 2010 Sep;28(3):190-7.

11. Ward KK, Roncancio AM, Berenson AB. Cultural adaptation among Hispanic women as related to awareness and acquisition of emergency contraception. Contraception. 2010 Dec;82(6):534-7.

12. Lorenzo-Blanco EI, Unger JB, Ritt-Olson A, Soto D, Baezconde-Garbanati L. Acculturation, gender, depression, and cigarette smoking among U.S. Hispanic youth: the mediating role of perceived discrimination. J Youth Adolesc. 2011 Nov;40(11):1519-33.

13. Gorman BK, Read JG, Krueger PM. Gender, acculturation, and health among Mexican Americans. J Health Soc Behav. 2010 Dec;51(4):440-57.

14. Pérez-Escamilla R, Garcia J, Song D. HEALTH CARE ACCESS AMONG HISPANIC IMMIGRANTS: ¿ALGUIEN ESTÁ ESCUCHANDO? [IS ANYBODY LISTENING?]. NAPA Bull. 2010 Nov 1;34(1):47-67.

15. Berdahl TA, Torres Stone RA. Examining Latino differences in mental healthcare use: the roles of acculturation and attitudes towards healthcare. Community Ment Health J. 2009 Oct;45(5):393-403. 
16. Zambrana RE, Carter-Pokras O. Role of acculturation research in advancing science and practice in reducing health care disparities among Latinos. Am J Public Health. 2010 Jan;100(1):18-23.

17. Solomon LS, Hays RD, Zaslavsky AM, Ding L, Cleary PD. Psychometric properties of a group-level Consumer Assessment of Health Plans Study (CAHPS) instrument. Med Care. 2005 Jan;43(1):53-60.

18. Ware JE, Kosinski M, Keller SD. A 12-Item Short-Form Health Survey: Construction of Scales and Preliminary Tests of Reliability and Validity. Medical Care 1996;34(3):220233.

19. Marin G, Gamba RJ. A New Measurement of Acculturation for Hispanics: The Bidimensional Acculturation Scale for Hispanics (BAS). Hispanic Journal of Behavioral Sciences 1996;18(3):297-316.

20. Institute of Medicine: Committee on Health Care in America. Crossing the quality chasm: A new health system for the 21st century. National Academy Press; 2001.

21. Katz JN, Lyons N, Wolff LS, Silverman J, Emrani P, Holt HL, Corbett KL, Escalante A, Losina E. Medical decision-making among Hispanics and non-Hispanic Whites with chronic back and knee pain: a qualitative study. BMC Musculoskelet Disord. 2011 Apr 21;12:78.

22. Antecol H, Bedard K. Unhealthy assimilation: why do immigrants converge to American health status levels? Demography. 2006 May;43(2):337-60.

23. Akresh IR, Frank R. Health selection among new immigrants. Am J Public Health. 2008 Nov;98(11):2058-64.Diwan S. Limited English proficiency, social network 
characteristics, and depressive symptoms among older immigrants. J Gerontol B Psychol Sci Soc Sci. 2008 May;63(3):S184-91.

24. Johnson KL, Carroll JF, Fulda KG, Cardarelli K, Cardarelli R. Acculturation and selfreported health among Hispanics using a socio-behavioral model: the North Texas Healthy Heart Study. BMC Public Health. 2010 Feb 2;10:53.

25. Schwartz A, Hasnain M, Eiser AR, Lincoln E, Elstein AS. Patient-physician fit: an exploratory study of a multidimensional instrument. Med Decis Making. 2006 MarApr;26(2):122-33. 
Table 1: Participant characteristics

\begin{tabular}{|c|c|c|c|c|c|}
\hline & \multirow{2}{*}{$\begin{array}{l}\text { Caucasian } \\
(n=291)\end{array}$} & \multirow{2}{*}{$\begin{array}{l}\text { African- } \\
\text { American } \\
(\mathbf{n}=\mathbf{3 0 3})\end{array}$} & \multicolumn{2}{|c|}{ Hispanic $(n=271)$} & \multirow{2}{*}{$\begin{array}{l}\text { Overall* } \\
(\mathrm{n}=\mathbf{8 8 1})\end{array}$} \\
\hline & & & $\begin{array}{l}\text { Unacculturated } \\
(n=90)\end{array}$ & $\begin{array}{l}\text { Biculturated } \\
(n=181)\end{array}$ & \\
\hline \multicolumn{6}{|l|}{$\begin{array}{l}\text { Primary language } \\
\chi^{2}(3)=630, p<.001\end{array}$} \\
\hline English & $\begin{array}{l}291 \\
(100 \%)\end{array}$ & $303(100 \%)$ & $3(3 \%)$ & $152(84 \%)$ & $\begin{array}{l}749 \\
(85 \%)\end{array}$ \\
\hline Spanish & 0 & 0 & $87(97 \%)$ & $29(16 \%)$ & $\begin{array}{l}116 \\
(15 \%)\end{array}$ \\
\hline \multicolumn{6}{|l|}{$\begin{array}{l}\text { Age category (years) } \\
\chi^{2}(18)=123, p<.001\end{array}$} \\
\hline $18-24$ & $129(44 \%)$ & $94(31 \%)$ & $10(11 \%)$ & $93(51 \%)$ & $\begin{array}{l}326 \\
(37 \%)\end{array}$ \\
\hline $25-34$ & $129(44 \%)$ & $91(30 \%)$ & $41(46 \%)$ & $65(36 \%)$ & $\begin{array}{l}326 \\
(37 \%)\end{array}$ \\
\hline $35-44$ & $20(7 \%)$ & $53(18 \%)$ & $23(26 \%)$ & $15(8 \%)$ & $\begin{array}{l}111 \\
(13 \%)\end{array}$ \\
\hline $45-54$ & $10(3 \%)$ & $35(12 \%)$ & $8(9 \%)$ & $6(3 \%)$ & $59(7 \%)$ \\
\hline $55-64$ & $2(1 \%)$ & $18(6 \%)$ & $5(6 \%)$ & $1(1 \%)$ & $26(3 \%)$ \\
\hline $65-74$ & 0 & $8(3 \%)$ & $3(3 \%)$ & 0 & $11(1 \%)$ \\
\hline 75 and $>$ & 0 & $1(0.3 \%)$ & 0 & $1(0.6 \%)$ & $2(0 \%)$ \\
\hline \multicolumn{6}{|l|}{$\begin{array}{l}\text { Gender } \\
\chi^{2}(3)=42, p<.001\end{array}$} \\
\hline Male & $113(39 \%)$ & $98(32 \%)$ & $6(7 \%)$ & $38(21 \%)$ & $\begin{array}{l}255 \\
(29 \%)\end{array}$ \\
\hline Female & $178(61 \%)$ & $201(68 \%)$ & $84(93 \%)$ & $143(79 \%)$ & $\begin{array}{l}606 \\
(71 \%)\end{array}$ \\
\hline \multicolumn{6}{|l|}{$\begin{array}{l}\text { Education } \\
\chi^{2}(15)=458, p<.001\end{array}$} \\
\hline $8^{\text {th }}$ grade or less & 0 & $2(1 \%)$ & $34(38 \%)$ & $5(3 \%)$ & $41(5 \%)$ \\
\hline Some high school & $2(1 \%)$ & $8(3 \%)$ & $13(14 \%)$ & $24(13 \%)$ & $47(5 \%)$ \\
\hline $\begin{array}{l}\text { High school graduate or } \\
\text { GED }\end{array}$ & $8(3 \%)$ & $48(16 \%)$ & $36(40 \%)$ & $34(19 \%)$ & $\begin{array}{l}126 \\
(14 \%)\end{array}$ \\
\hline $\begin{array}{l}\text { Some college or 2-yr } \\
\text { degree }\end{array}$ & $96(33 \%)$ & $114(38 \%)$ & $3(3 \%)$ & $70(39 \%)$ & $\begin{array}{l}283 \\
(32 \%)\end{array}$ \\
\hline 4-yr college degree & $86(30 \%)$ & $72(24 \%)$ & $3(3 \%)$ & $29(16 \%)$ & $\begin{array}{l}190 \\
(22 \%)\end{array}$ \\
\hline$>4$-yr college degree & $99(34 \%)$ & $56(18 \%)$ & $1(1 \%)$ & $19(10 \%)$ & $\begin{array}{l}175 \\
(20 \%)\end{array}$ \\
\hline
\end{tabular}

"Includes missing race $(\mathrm{n}=16)$ 
Table 2: Site characteristics

\begin{tabular}{|c|c|c|c|c|}
\hline & Site $1(n=16)$ & Site $2(n=43)$ & Site $3(n=209)$ & Site $4(n=593)$ \\
\hline \multicolumn{5}{|l|}{$\begin{array}{l}\text { Gender } \\
\chi^{2}(3)=81, p<.001\end{array}$} \\
\hline Male & 7 & 16 & 10 & 219 \\
\hline Female & 9 & 27 & 199 & 372 \\
\hline \multicolumn{5}{|l|}{$\begin{array}{l}\text { Age category (years) } \\
\chi^{2}(18)=58, p<.001\end{array}$} \\
\hline $18-24$ & 9 & 10 & 72 & 235 \\
\hline $25-34$ & 4 & 10 & 89 & 226 \\
\hline $35-44$ & 2 & 7 & 28 & 73 \\
\hline $45-54$ & 1 & 7 & 13 & 35 \\
\hline $55-64$ & 0 & 4 & 3 & 18 \\
\hline $65-74$ & 0 & 4 & 3 & 4 \\
\hline 75 and $>$ & 0 & 1 & 1 & 0 \\
\hline \multicolumn{5}{|l|}{$\begin{array}{l}\text { Ethnicity } \\
\chi^{2}(9)=485, p<.001\end{array}$} \\
\hline Caucasian & 9 & 7 & 12 & 259 \\
\hline African-American & 5 & 35 & 13 & 236 \\
\hline $\begin{array}{l}\text { Hispanic } \\
\text { (unacculturated) }\end{array}$ & 0 & 0 & 86 & 3 \\
\hline Hispanic (biculturated) & 2 & 1 & 92 & 85 \\
\hline
\end{tabular}

Note: Site information was not recorded for 20 respondents, who are excluded from this table. 
Table 3: Means and standard deviations of CAHPS and SF-12 components

\begin{tabular}{|c|c|c|c|c|c|}
\hline & \multirow{2}{*}{$\begin{array}{l}\text { Caucasian } \\
(n=291)\end{array}$} & \multirow{2}{*}{$\begin{array}{l}\text { African- } \\
\text { American } \\
(\mathbf{n}=\mathbf{3 0 3})\end{array}$} & \multicolumn{2}{|c|}{ Hispanic $(\mathrm{n}=271)$} & \multirow{2}{*}{$\begin{array}{l}\text { Overall* } \\
(n=881)\end{array}$} \\
\hline & & & $\begin{array}{l}\text { Unacculturated } \\
(n=90)\end{array}$ & $\begin{array}{l}\text { Biculturated } \\
(n=181)\end{array}$ & \\
\hline $\begin{array}{l}\text { Overall } \\
\text { ("Rate this doctor", 0-10) }\end{array}$ & $8.8(1.5)^{\mathrm{a}, \mathrm{b}, \mathrm{c}}$ & $9.0(1.3)^{\mathrm{a}, \mathrm{d}}$ & $9.7(0.8)^{b, d, e}$ & $9.1(1.3)^{\mathrm{c}, \mathrm{e}}$ & $9.0(1.4)$ \\
\hline $\begin{array}{l}\text { Recommend } \\
\text { ("Would you recommend } \\
\text { this doctor?", 1-4) }\end{array}$ & $3.7(0.7)^{\mathrm{a}, \mathrm{b}, \mathrm{c}}$ & $3.8(0.6)^{\mathrm{a}, \mathrm{d}}$ & $3.9(0.3)^{b, d}$ & $3.8(0.5)^{\mathrm{c}}$ & $3.8(0.6)$ \\
\hline $\begin{array}{l}\text { Shared decision making } \\
(0-1)^{1}\end{array}$ & $0.4(0.5)^{\mathrm{a}, \mathrm{b}}$ & $0.5(0.5)^{\mathrm{c}, \mathrm{d}}$ & $0.8(0.4)^{\mathrm{a}, \mathrm{c}, \mathrm{e}}$ & $0.6(0.5)^{\mathrm{b}, \mathrm{d}, \mathrm{e}}$ & $0.5(0.5)$ \\
\hline Communication (1-6) ${ }^{2}$ & $5.6(0.7)$ & $5.5(0.7)^{\mathrm{a}}$ & $5.8(0.6)^{\mathrm{a}}$ & $5.7(0.6)$ & $5.6(0.7)$ \\
\hline $\begin{array}{l}\text { Provider communication } \\
(0-1)^{3}\end{array}$ & $0.8(0.3)^{\mathrm{a}, \mathrm{b}}$ & $0.9(0.2)$ & $0.9(0.3)^{\mathrm{a}}$ & $0.9(0.2)^{b}$ & $0.9(0.3)$ \\
\hline Other providers (1-6) ${ }^{4}$ & $5.3(1.0)$ & $5.3(0.9)$ & $6.0(0.8)$ & $5.4(0.9)$ & $5.4(0.9)$ \\
\hline $\begin{array}{l}\text { Other providers overall } \\
\text { ("Rate other providers", 0- } \\
\text { 10) }\end{array}$ & $8.2(1.8)^{\mathrm{a}}$ & $8.3(1.8)^{b}$ & $9.3(1.2)^{\mathrm{a}, \mathrm{b}, \mathrm{c}}$ & $8.5(1.9)^{\mathrm{c}}$ & $8.4(1.8)$ \\
\hline Helpful staff (1-6) ${ }^{5}$ & $5.3(0.9)^{\mathrm{a}}$ & $5.4(0.9)^{b}$ & $5.7(0.7)^{\mathrm{a}, \mathrm{b}, \mathrm{c}}$ & $5.4(1.2)^{\mathrm{c}}$ & $5.3(0.9)$ \\
\hline $\begin{array}{l}\text { Getting appointments (1- } \\
6)^{6}\end{array}$ & $4.9(1.4)^{\mathrm{a}}$ & $4.8(1.3)$ & $4.6(1.1)^{\mathrm{a}}$ & $4.7(1.2)$ & $4.8(1.3)$ \\
\hline $\begin{array}{l}\text { SF-12 Physical Component } \\
\text { Score }\end{array}$ & $53.3(7.3)^{\mathrm{a}, \mathrm{b}}$ & $48.9(10.2)^{\mathrm{a}, \mathrm{c}}$ & $47.6(8.3)^{b, d}$ & $52.0(6.9)^{\mathrm{c}, \mathrm{d}}$ & $50.9(8.7)$ \\
\hline $\begin{array}{l}\text { SF-12 Mental Component } \\
\text { Score }\end{array}$ & $52.6(10.4)^{\mathrm{a}, \mathrm{b}}$ & $53.2(9.4)^{\mathrm{c}, \mathrm{d}}$ & $47.2(11.4)^{\mathrm{a}, \mathrm{c}}$ & $49.3(10.9)^{\mathrm{b}, \mathrm{d}}$ & $\begin{array}{l}51.5 \\
(10.5) \\
\end{array}$ \\
\hline
\end{tabular}

* Including missing race $(\mathbf{n}=16)$

${ }^{a-e}$ Pairs of means that are significantly different $(p<.05)$ as tested via contrasts in one-way ANOVA are marked with common alphabetic superscripts.

${ }^{1}$ Composed of mean of CAG items SD1 ("Did doctor tell you there was more than one choice?"), SD2 ("Did doctor talk with you about pros and cons of each choice?") and SD3 ("Did doctor ask which choice you thought was best for you?"), each scored 1 for "yes" and 0 for "no".

${ }^{2}$ Composed of mean of CAG items Q14 ("How often provider explained things in a way that was easy to understand"), Q15 (“How often provider listened carefully to you”), Q17 (“How often provider gave easy to understand instructions"), Q18 ("How often provider knew important information about your medical history"), Q19 ("How often provider showed respect for what you had to say"), and Q20 ("How often provider spent enough time with you"), each rated on a 6-point scale anchored by "never" and "always".

${ }^{3}$ Composed of mean of CAG items C4 ("Did you feel the doctor really cared about you as a person?"), C6 ("Was doctor condescending, sarcastic, or rude?"), C9a-C9f (“Did doctor give you complete and accurate information 
about (a) tests, (b) choices, (c) treatment, (d) plan for your care, (e) medications, (f) follow-up care?'), each scored 1 for "yes" and 0 for "no".

${ }^{4}$ Composed of mean of CAG items OD2 ("How often other providers explained things in a way that was easy to understand"), OD3 ("How often other providers listened carefully to you"), OD5 ("How often other providers gave you easy to understand instructions"), and OD7 ("How often other providers spent enough time with you"), each rated on a 6-point scale anchored by "never" and "always".

${ }^{5}$ Composed of mean of CAG items Q24 (“How often were staff as helpful as you thought they should be?") and Q25 (“How often did staff treat you with courtesy and respect?"), each rated on a 6-point scale anchored by "never" and "always".

${ }^{6}$ Composed of mean of CAG items Q6 ("How often did you get appointment for care you needed right away as soon as you thought you needed?"), Q8 (“How often did you get appointment for routine care as soon as you thought you needed?"), Q10 (“When you phoned the office during regular hours, how often did you get an answer the same day?”), Q12 (“When you phoned the office after regular hours, how often did you get an answer as soon as you needed?"), Q13 (“How often did you see this doctor within 15 minutes of your appointment time?"), each rated on a 6-point scale anchored by "never" and "always". 
Table 4. Standardized coefficients for multiple regression analysis models, by outcome

\begin{tabular}{|c|c|c|c|c|c|c|c|c|c|}
\hline & Overall & Recommend & $\begin{array}{c}\text { Shared } \\
\text { decision } \\
\text { making } \\
\end{array}$ & Communication & $\begin{array}{c}\text { Provider } \\
\text { communication }\end{array}$ & $\begin{array}{c}\text { Other } \\
\text { providers }\end{array}$ & $\begin{array}{c}\text { Other } \\
\text { providers } \\
\text { overall } \\
\end{array}$ & $\begin{array}{l}\text { Helpful } \\
\text { staff }\end{array}$ & $\begin{array}{c}\text { Getting } \\
\text { appointments }\end{array}$ \\
\hline Male gender & .085 & .036 & $-.137 *$ & .069 & .101 & -.099 & .035 & $.122^{*}$ & $.128^{*}$ \\
\hline \multicolumn{10}{|l|}{ Age } \\
\hline $18-24$ & - & - & - & - & - & - & - & - & - \\
\hline $25-34$ & -.018 & -.019 & .054 & -.071 & .005 & -.058 & .041 & -.060 & -.088 \\
\hline $35-44$ & .039 & -.040 & .063 & -.015 & -.045 & -.030 & .023 & -.044 & -.045 \\
\hline $45+$ & .065 & .048 & $.135 *$ & .033 & .096 & $.155^{*}$ & $.183^{*}$ & -.025 & -.114 \\
\hline \multicolumn{10}{|l|}{ Race/Ethnicity } \\
\hline Caucasian & - & - & - & - & - & - & - & - & - \\
\hline African American & .090 & .089 & .076 & -.026 & .037 & -.023 & -.005 & .045 & .033 \\
\hline $\begin{array}{l}\text { Unacculturated } \\
\text { Hispanic }\end{array}$ & $.193 *$ & $.139 \%$ & $.160 \%$ & .084 & .067 & .092 & $.136^{*}$ & $.168^{*}$ & .048 \\
\hline $\begin{array}{l}\text { Biculturated } \\
\text { Hispanic } \\
\end{array}$ & .124 & .106 & $.218 *$ & .112 & .109 & .036 & .062 & $.141^{*}$ & .042 \\
\hline \multicolumn{10}{|l|}{ Education } \\
\hline $\begin{array}{l}\text { Less than high } \\
\text { school graduate }\end{array}$ & - & - & - & - & - & - & - & - & - \\
\hline $\begin{array}{c}\text { High school } \\
\text { graduate or GED }\end{array}$ & -.079 & -.072 & .033 & .019 & .073 & .029 & -.042 & .051 & -.026 \\
\hline $\begin{array}{l}\text { Some college or } \\
\text { 2-yr degree }\end{array}$ & -.072 & -.070 & -.110 & -.035 & -.039 & .039 & -.091 & -.113 & -.026 \\
\hline $\begin{array}{l}\text { 4-yr college } \\
\text { degree }\end{array}$ & -.128 & -.111 & -.151 & -.076 & -.009 & .011 & -.112 & -.083 & -.059 \\
\hline $\begin{array}{l}>4-y r \text { college } \\
\text { degree }\end{array}$ & -.093 & -.141 & .018 & -.016 & -.113 & -.071 & $-.223^{*}$ & -.155 & -.149 \\
\hline $\begin{array}{l}\text { SF-12 Physical } \\
\text { health composite } \\
\text { score }\end{array}$ & .122 & .112 & -.056 & $.147 *$ & .084 & .122 & $.149 *$ & .043 & $.180 \%$ \\
\hline $\begin{array}{l}\text { SF-12 Mental } \\
\text { health composite } \\
\text { score }\end{array}$ & $.198 *$ & .085 & -.061 & $.200 *$ & .106 & $.208 *$ & $.300 *$ & $.133 *$ & $.266 \%$ \\
\hline $\mathbf{R}^{2}$ & $.088 *$ & .048 & $.180 *$ & $.076 *$ & $.060 *$ & $.078 *$ & $.137 *$ & $.110 *$ & $.170 *$ \\
\hline
\end{tabular}

